\title{
Proteolytic activity in the human stomach during digestion and its correlation with the augmented histamine test
}

\author{
S. J. RUNE ${ }^{1}$ \\ From Surgical Department $A$ and the Department of Clinical Chemistry, \\ Bispebjerg Hospital, Copenhagen, Denmark
}

EDITORIAL SYNOPSIS A highly significant correlation has been found between proteolytic activity in the stomach during digestion of food and the level of gastric secretion during histamine stimulation. It is concluded that the augmented histamine test gives an acceptable impression of the secretory activity of the stomach during normal digestion. This is not true for basal secretion.

The gastric secretory capacity may be determined in man by the augmented histamine test introduced by Kay (1953). The gastric juice aspirated during this test is the response to a maximal histamine stimulation and the output of hydrochloric acid has been shown to be closely correlated to the parietal cell mass (Card and Marks, 1960).

The variations in concentration and volume of the hydrochloric acid secreted during this test show a significant tendency toward a higher secretion of acid in patients with duodenal ulcer than in normal individuals. As a consequence the augmented histamine test is of considerable help in the establishment of the diagnosis and it is today widely used as a guide to treatment. These clinical applications of the test results are based on the assumption that there exists a close correlation between the result of the augmented histamine test and the gastric secretion when food is used as a physiological stimulus. It is therefore important to measure the relationship between the gastric secretion stimulated by food and the response to maximal histamine stimulation.

Quantitative determination of the acid secreted during digestion of normal food is not possible because juice with an unknown composition will leave the stomach through the pylorus before the stomach contents can be aspirated. As a consequence no reports exist giving quantitative determinations of the gastric secretion after ingestion of normal

${ }^{1}$ Present address: Department of Clinical Physiology, Bispebjerg Hospital, Copenhagen. solid food in man. Harrower, Brook, and Cooper (1956) measured the volume of gastric juice aspirated 20 minutes after a broth meal was taken. They found a secretion not significantly different from the basal secretion. Hunt (1950) showed a significant correlation between the secretion stimulated by histamine and that stimulated by a 'meal' composed of indigestible pectin. Marks and Shay (1960) compared the results of the augmented histamine test and the Ewald test meal, consisting of two biscuits and $350 \mathrm{ml}$. of water. They found a significant correlation in persons without duodenal ulcer, but in patients with this disease there was a lack of significant correlation.

This paper describes the proteolytic activity in the human stomach during digestion of food with a normal protein content and its correlation with the augmented histamine test. A comparison is made between the proteolytic activity in patients with duodenal ulcer and in normal individuals.

MATERIAL

Proteolytic activity was measured in 80 patients aged between 24 and 84 years. Twenty of these individuals were considered normal from a gastroenterological point of view, as the majority were suffering from inguinal hernia only. Thirty-one patients had a diagnosis of duodenal ulcer, and in 18 of these it was verified by operation. Of the 80 persons, 74 underwent the augmented histamine test a few days before or after proteolytic activity was measured. Six individuals belonging to the normal group refused to submit to the augmented histamine test. 
METHODS

For the measurement of the proteolytic activity in the stomach, a liquid standard meal with a composition like normal food was used. A tracer amount of radioactive albumin was mixed with the meal and by small aspirations of the stomach contents the digestion of the albumin could be followed.

The standard meal was made from a dehydrated mixture of protein (mostly casein), fat, and sugar. By adding water the volume of the meal was brought to $150 \mathrm{ml}$. with a protein content of $10 \%$, of fat $3 \%$, and of sugar $15 \%$. To each standard meal $5 \mu \mathrm{c}{ }^{131} \mathrm{I}$-albumin was added. When the patient had swallowed the meal, a stomach tube was passed through the nostril and $5 \mathrm{ml}$. stomach contents was aspirated at $10,30,50,70$, and 90 minutes after the ingestion of food. At $90 \mathrm{~min}$. the stomach was emptied through the tube.

The radioactivity in each of the five samples was measured in a scintillation counter, and the albumin digestion was expressed as described by Klotz and Duvall (1957) by the activity soluble in $30 \%$ T.C.A. as a percentage of the total activity in the sample. A correction was made for the 1 to $3 \%$ preformed soluble ${ }^{131}$ I activity in the meal.

Incubation of ${ }^{131} \mathrm{I}$-albumin with $0.2 \mathrm{~N}$ hydrochloric acid showed this to be without 'proteolytic effect'.

The augmented histamine test was performed as described by Kay (1953) with continuous suction on the stomach tube, the correct position being verified radiologically. The dose of histamine was $0.04 \mathrm{mg}$. histamine diphosphate per kilogram body weight injected subcutaneously.

\section{RESULTS}

The rate of albumin digestion in the stomach was found to be nearly constant in the 90 minutes during which the stomach content was aspirated. Figure 1 shows the progress in three patients with different proteolytic activities. The proteolytic activity is expressed as the percentage of digested albumin found 50 minutes after the meal had been given. In this way the three examples shown in Fig. 1 represent the proteolytic activities $55 \%, 30 \%$, and $3 \%$.

All the 80 persons investigated showed some proteolytic activity in the stomach, ranging from $2 \%$ to $65 \%$.

The mean proteolytic activity found in the group consisting of 20 normal persons was $26 \%$ (S.D. $12 \%$ ). Eighteen patients with duodenal ulcer, verified at operation, showed a mean activity of $42 \%$ (S.D. $13 \%$ ). The difference between these two groups is significant $(t: 3.97, p<0.001)$. The individual values for proteolytic activity in the two groups are shown in Figure 2.

The correlation between the proteolytic activity in the stomach during digestion of food and the gastric secretion under basal conditions and during

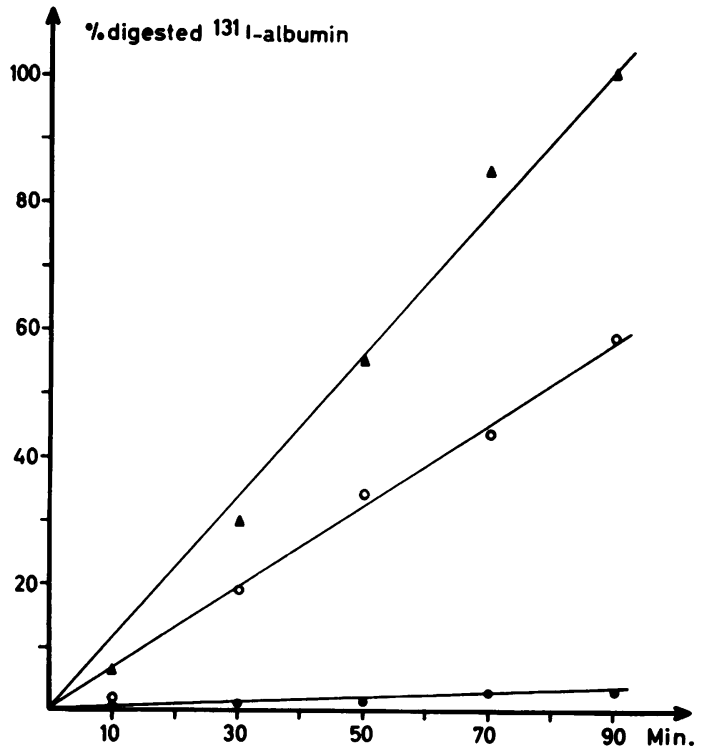

FIG. 1. The digestion of radioactive albumin in the stomach of three persons taking a standard meal at zero time.

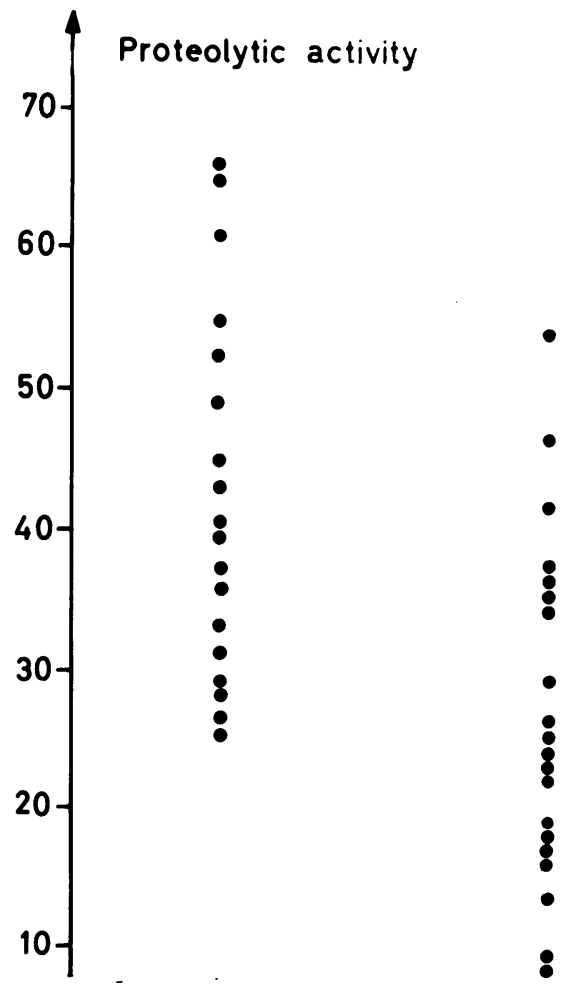

FIG. 2. The proteolytic activity in the stomach during food digestion in 18 patients with duodenal ulcer (left) and in 20 normal individuals (right). 
the augmented histamine test was measured in 74 persons. A highly significant $(P<0.001)$ correlation was found between the proteolytic activity and the histamine-stimulated secretion. The coefficients of correlation (r) are: proteolytic activity-maximal acidity, $\mathrm{r}=0.47$; proteolytic activity-maximal acid output, $\mathrm{r}=0.64$; proteolytic activity-maximal volume, $\mathrm{r}=0.72$.

A lower, but still significant $(P<0.001)$, correlation existed between the proteolytic activity and the basal secretion. The coefficients of correlation are: proteolytic activity-acidity, $\mathrm{r}=0.44$; proteolytic activity-acid output, $\mathrm{r}=0.38$; proteolytic activityvolume, $\mathrm{r}=0.55$.

Five patients showed achlorhydria according to the definition given by Callender, Retief, and Witts (1960). Proteolytic activity in this group varied from $8 \%$ to $35 \%$ with an average of $18 \%$.

\section{DISCUSSION}

Digestion of ${ }^{131} \mathrm{I}$-albumin in the stomach is dependent on peptidase activity, and the index of the rate of digestion employed may be considered a measure of the proteolytic activity. Using a liquid standard meal with a composition like normal food it can be assumed that the measured activity is in agreement with that normally occurring in the stomach during digestion of food.

The rate of albumin digestion was found to be nearly constant through the first 90 minutes after digestion started. The increasing amount of acid and pepsin secreted during this period seems to contradict this result, but formation of pepsin inhibitors during protein digestion can explain the relationship (Le Veen and Hallinger, 1947; Bucher, Grossman, and Ivy, 1945; Chinn, Book, and Beams, 1951).

The highly significant correlation found between proteolytic activity in the stomach during digestion of food and gastric secretion during histamine stimulation may be interpreted as a confirmation of the assumption that the augmented histamine test gives an acceptable impression of the secretory capacity during physiological stimulation.

A very high correlation has been reported between acid secretion during the augmented histamine test and the parietal cell mass (Card and Marks, 1960). It may therefore be concluded from the results reported here that this anatomical factor is also of importance for the secretion caused by taking food.

The low correlation found between proteolytic activity and the basal secretion confirms what has keen shown by others (Ball, 1961; Sircus, 1950) that this secretion gives no useful information on the secretory capacity.
Proteolytic activity is shown to be significantly higher in the stomach when a duodenal ulcer exists than in the normal stomach. Taylor (1959a) has reported that some patients with duodenal ulcer secreted a pepsin with three $p \mathrm{H}$ optimas instead of the normal two optimas. This finding cannot explain the higher proteolytic activity reported here in patients with duodenal ulcer because the relation between proteolytic activity and the volume secreted during the augmented histamine test in normal persons did not disagree with that found in patients with duodenal ulcer.

The greater response of acid to maximal histamine stimulation of the stomach in duodenal ulcer patients is associated with a similarly greater parietal cell mass (Cox, 1952), and the higher proteolytic activity during digestion of food has been shown in this study to correlate with their maximum acid secretory capacity and may reflect a correspondingly greater number of pepsin-secreting cells in the stomach of patients with duodenal ulcer. However, the easier conditions for pepsin activity in a stomach able to acidify and dilute food shortly after its ingestion could be responsible for the higher proteolytic activity found in this group.

The proteolytic activity found in five patients with achlorhydria must be caused by refluxed pancreatic and intestinal juice, because the $p \mathrm{H}$ in these stomachs makes significant gastric proteinase activity impossible (Taylor, 1959b).

\section{SUMMARY}

A tracer amount of ${ }^{131} \mathrm{I}$-albumin was added to a liquid standard meal containing $10 \%$ protein. The albumin digestion was measured in small aspirated samples of the stomach contents at 10, 30, 50, 70, and 90 minutes after ingestion of the meal. The content of ${ }^{131}$ I soluble in T.C.A. as a percentage of the total radioactivity in the sample aspirated at 50 minutes was used as an index of the proteolytic activity in the stomach. A highly significant correlation was found between proteolytic activity during food digestion and the gastric secretion of acid during the augmented histamine test $(r=0.64)$. A low but significant correlation was found between proteolytic activity and the basal secretion of acid $(r=0.38)$. The average proteolytic activity in 18 patients with duodenal ulcer was $42 \%$ (S.D. $=13 \%$ ) compared with $26 \%$ (S.D. $=12 \%$ ) in 20 normal individuals. This difference is highly significant $(\mathrm{p}<0.001)$.

I am grateful to Dr. K. H. Køster, chief of the surgical department where this work was done, for his advice and for facilities for this study. 


\section{REFERENCES}

Ball, P. A. J. (1961). The secretory background to gastric ulcer. Lancet, 1, 1363-1365.

Bucher, G. R., Grossman, M. I., and Ivy, A. C. (1945). A pepsin method: the role of dilution in the determination of peptic activity. Gastroenterology, 5, 501-511.

Callender, S. T., Retief, F. P., and Witts, L. J. (1960). The augmented histamine test with special reference to achlorhydria. Gut, 1, 326-336.

Card, W. I., and Marks, I. N. (1960). The relationship between the acid output of the stomach following 'maximal' histamine stimulation and the parietal cell mass. Clin. Sci., 19, 147-163.

Chinn, A. B., Book, D. T., and Beams, A. J. (1951). Studies on pepsin secretion. I. Nocturnal and hypoglycemic secretion in patients with duodenal ulcer and without gastrointestinal disease. Gastroenterology, 18, 427-437.

Cox, A. J. (1952). Stomach size and chronic peptic ulcer. Arch. Path., $54,407$.

Harrower, H. W., Brook, D. L., and Cooper, P. (1956). A comparison of gastric pepsin and uropepsin in patients with duodenal ulcer, pre- and postoperative. Ann. Surg., 144, 816-822.
Hunt, J. N. (1950). An interpretation of the histamine test of gastric secretion. Gastroenterology, 16, 231-240.

Kay, A. W. (1953). Effect of large doses of histamine on gastric secretion of $\mathrm{HCl}$; an augmented histamine test. Brit. med. J., 2, 77-80.

Klotz, A. P., and Duvall, M. R. (1957). The laboratory determination of pepsin in gastric juice with radioactive iodinated albumin. J. Lab. clin. Med., 50 (5), 753-757.

Le Veen, H. H., and Hallinger, L. (1947). The role of pepsin, peptic inhibitory substances, and hydrochloric acid in normal subjects and in the production of peptic ulcers. J. clin. Invest., 26, 761-772.

Marks, I. N., and Shay, H. (1960). Augmented histamine test, Ewald test meal, and Diagnex test. Comparison of results. Amer. J. dig. Dis., 5, 1-23.

Sircus, W. (1950). In Peptic Ulceration: a Symposium for Surgeons, edited by C. Webb and J. Kyle, pp. 28-32. Livingstone, Edinburgh.

Taylor,W. H. (1959a). Gastric proteolysis in disease. 2. J. clin. Path., 12, 338-343.

- (1959b). Studies on gastric proteolysis. 4. Proteinase activity of gastric juice and gastric-mucosal extracts at $p \mathrm{H} 6$ to 8 . Biochem. J., 71, 626-632. 